\title{
Performance Analysis of Transcritical Carbon Dioxide Rankine Cycle with Regenerator
}

\author{
Aklilu T. Baheta ${ }^{1, *}$, Sintayehu M. Hailegiorgis ${ }^{1}$, Ahmed N. Oumer ${ }^{2}$ and Shaharin Anwar B \\ Sulaiman $^{1}$ \\ ${ }^{1}$ Universiti Teknologi PETRONAS, 31750 Tronoh, Perak, Malaysia \\ ${ }^{2}$ Universiti Malaysia Pahang, Faculty of Mechanical Engineering, 2600 Pekan, Pahang, Malaysia
}

\begin{abstract}
Transcritical carbon dioxide Rankine cycle (TCRC) has a potential to convert low grade heat source into power. Thus, the objective of this paper is to evaluate TCRC performance based on the first and the second law of thermodynamics for wide and different operating conditions. To address this, TCRC thermal efficiency, exergetic efficiency, utilization ratio and the exergy destruction of the components are analyzed parametrically. Engineering Equation Solver (EES) is used to solve the set of equations and to evaluate the working fluid properties at the given conditions. For the analysis compressor efficiency, turbine efficiency and effectiveness of the regenerator are assumed to be $0.9,0.9$ and 0.95 , respectively. The pump inlet pressure was assumed to be $6.2 \mathrm{MPa}$. It is found that at $10 \mathrm{MPa}$ turbine inlet pressure $240^{\circ} \mathrm{C}$ is the optimal turbine inlet temperature operating condition. The percentage of exergy destructions at $240^{\circ} \mathrm{C}$ turbine inlet temperature are $0.94,4.53,9.55,41.23$, and 43.74 by the pump, turbine, condenser, heater and regenerator, respectively. Hence, the highest and the smallest exergy destructions are in the regenerator and the pump. This study will help to select the potential component for further improvement.
\end{abstract}

\section{Introduction}

Low graded heat sources and waste heat can be obtained from solar, geothermal, power plant exhaust gases. Utilization of these low grade heat energies is drawing attention and also gives an opportunity towards sustainable energy future and low environmental pollution. However, the energy contained in most low graded heats is in the form of sensible heat. Thus, the heat transfer is not isothermal process; rather it is at gliding temperature as the amount of heat source is limited. Furthermore, one of the challenges is minimizing the irreversibilities while heating up the working fluid particularly in the lower temperature for better efficiency and specific work [1]. This can be addressed if low critical temperature working fluid is used. Carbon dioxide $\left(\mathrm{CO}_{2}\right)$ has low critical temperature $\left(31.1^{\circ} \mathrm{C}\right)$ and thus the heating process is in the supercritical region. The main advantage of $\mathrm{CO}_{2}$ as a working fluid is the pinching that happened during the heating process of ORC is eliminated as the heating is in the supercritical region. Consequently, during heating process the temperature profile of the $\mathrm{CO}_{2}$ and the source heat will match and glide [2]. This will greatly reduce the irreversibility which in turn

*Corresponding author: aklilu.baheta@utp.edu.my 
improves the cycle thermal efficiency. Many researchers focused on the first law analysis of $\mathrm{CO}_{2}$ power cycles [3,4]. Several studies [3,5] have suggested Organic Rankine Cycles are suitable for low temperature heat sources than traditional power cycle, the one that uses steam as a working fluid. Because, the nature of the organic fluids and their mixture do not need to be superheated as they will not form liquid during their expansion [5]. However, ORC has limitation in that the heat transfer from the source stream to the working fluid (evaporation) takes place at constant temperature $[6,7]$ and that will introduce pinching effect [8]. If there is pinching, there is irreversibility which counter balances the effort to enhance the thermal efficiency of the cycle. This is not suitable for sensible heat sources such as waste heat.

Traditionally, energy analysis is used as a criterion for evaluating the performance of thermal systems. However, energy analysis does not distinguish the useful form from the total available energy. An exergy- based analysis is the analysis of a system based on both the first and the second law of thermodynamics that overcomes the limitation of an energybased analysis. A hypothetical transcritical carbon dioxide transcritical power cycle that used low grade energy heat source was analyzed by Emmanuel et al. [3]. Using genetic algorithm and artificial neural network Wang et al. [10] optimized the working parameters of supercritical $\mathrm{CO}_{2}$ power cycle for a fixed heat source condition. Ho et al. [11] compared the overall thermodynamic and exergy efficiencies of organic flash cycle with different organic working fluids Rankine cycles. However, each component performance was not studied. Recently, Kim et al. [12] analyzed hypothetically isothermal transcritical $\mathrm{CO}_{2}$ cycles with TES for electricity storage.

Even though, there are considerable prior research that have been done in the area of $\mathrm{CO}_{2}$ cycles a detailed component exergy performance analysis is not available. Most of the earlier analyses focused purely on exergy and energy analyses of the cycle. Exergy destruction is the measure of irreversibility that is the source of performance loss. Such information is useful when designing a thermal system or reducing sources of inefficiency in an existing system. Thus this research focuses on energy and exergy performance of carbon dioxide Transcritical Rankine cycle (TCRC) using modeling and simulation methods.

\section{Thermodynamic analysis of TCRC}

In order to do both the energy and exergetic analyses the component model is needed to be developed. To decrease the primary heat consumption a regenerator is introduced in the $\mathrm{CO}_{2}$ Rankine cycle as show in Figure 1 (a). The corresponding temperature entropy diagram of the cycle is shown in Figure 1 (b). Each component model is developed based on the first and the second laws of thermodynamics. The energies that can be considered in a control volume are flow work, heat transfer, work transfer and energy transfer with the mass.

In general the exergy rate balance for a system interacting with the surrounding temperature $T_{o}$ for one dimensional flow with single inlet and outlet flow, negligible kinetic and potential energies, under steady state condition for a unit mass flow rate is given by Eq. (1).

$$
\sum\left(1-T_{o} / T_{j}\right) q_{j}+\psi_{i}=\psi_{o}+\sum \psi_{w}+\dot{I}
$$

where $q_{j}$ is the time rate of heat transfer at the location on the boundary where the instantaneous temperature is $T_{j} ; \psi_{w}$ is the availability associated with the control volume work; $\psi=\left(h-h_{o}\right)-T_{o}\left(s-s_{o}\right)$ is the availability transfer associated with mass flow and

flow work at inlet $i$ and exit $o$, respectively; and $\dot{I}$ is the time rate of exergy destruction due to irreversibilities within the control volume. 
The energy and exergy analyses of the five processes of the cycle, as shown in Figure 1 (b), can be described as follows.

Energy and irreversibility in the pump: Represented by process 1-2, the work input for a given pump efficiency $\left(\eta_{p}\right)$ and the irreversibility are given by Eqs. (2) and (3).

$$
\begin{aligned}
& w_{p}=\left(h_{2 s}-h_{1}\right) / \eta_{p} \\
& \dot{I}=\left(h_{1}-h_{2}\right)-T_{o}\left(s_{1}-s_{2}\right)+w_{p}
\end{aligned}
$$

Energy and irreversibility in the regenerator: The behavior of $\mathrm{CO}_{2}$ is sensitive near to its critical point pressure and temperature. Due to the radical temperature and pressure dependence of specific heat, the temperature difference between the hot and the cold fluid varies widely within the regenerator. Thus, for the heat transfer enthalpy difference is used instead of the product of specific heats and temperature differences. All possible conditions are considered to calculate the maximum heat transfer. If $\quad T_{3 s}=T_{5}$ then $q_{\max }=h_{3 s}-h_{2}$ and for the case $T_{6 s}=T_{2}$ then $q_{\max }=h_{5}-h_{6 s}$. The minimum $q_{\max }$ is used to evaluate the actual exit enthalpies with an assumed regenerator effectiveness, $\varepsilon_{R}$.

$$
\begin{aligned}
& h_{3}=\varepsilon_{R} q_{\text {max }}+h_{2} \\
& h_{6}=h_{5}-\varepsilon_{R} q_{\max }
\end{aligned}
$$

Exergy destruction in the regenerator assuming no heat and work interaction with the surroundings is given by Eq. (6)

$$
I_{R}=\left(h_{5}-h_{6}\right)-\left(h_{3}-h_{2}\right)+T_{o}\left[\left(s_{6}-s_{5}\right)+\left(s_{3}-s_{2}\right)\right]
$$

Energy and irreversibility in condenser: The heat rejected to the heat sink is predicted by applying the energy equation on the condenser and is defined by Eq. (7).

$$
q_{c}=\left(h_{6}-h_{1}\right)
$$

The corresponding exergy destruction in the condenser is predicted by Eq. (8).

$$
I_{c}=\left(h_{6}-h_{1}\right)-T_{o}\left(s_{6}-s_{1}\right)
$$

Energy and irreversibility in the Gas heater: Two heat are supplied to the gas heater at isobaric condition. One from the regenerator, the heat that would have been wasted which is considered in the regenerator analysis. Another one is the primary heat input from the heat source $\left(q_{p h}\right)$.

$$
q_{p h}=\dot{m}\left(h_{4}-h_{3}\right)
$$




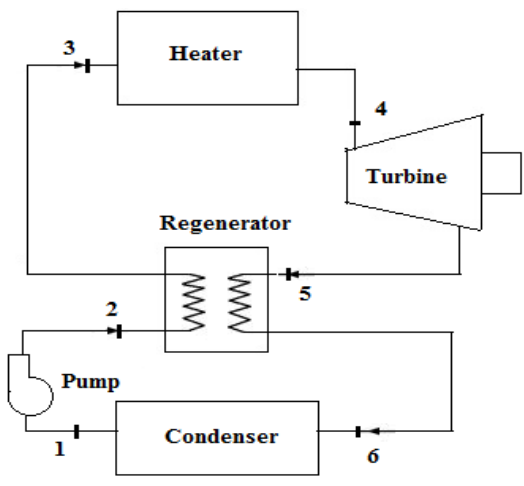

(a)

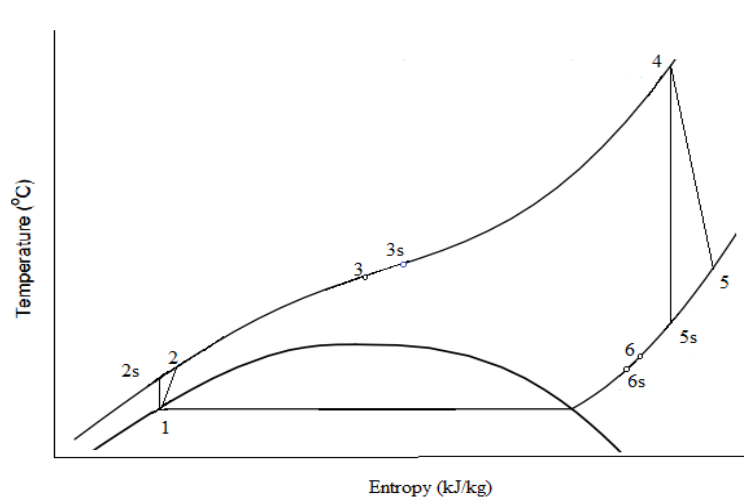

(b)

Figure. 1. Configuration and processes of a TCRC. (a) The configuration with regenerator, (b) The processes in a T-s diagram

The irreversibilities for the gas heater is derived from Eq (1) where $q_{j}=\left(h_{4}-h_{3}\right)$ and $T_{j}=T_{4}$ are substituted into the equation and after simplification it becomes

$$
I_{h}=\left(1-T_{o} / T_{4}\right)\left(h_{4}-h_{3}\right)+\left(h_{3}-h_{4}\right)-T_{o}\left(s_{3}-s_{4}\right)
$$

Energy and irreversibility in the Turbine: This is the component where the heat is converted into work. Ideally, the process is isentropic. However, there is no $100 \%$ efficient energy conversion. In order to account this isentropic efficiency of the turbine is considered. For the working fluid entering at state 4 and expending isentropically with state point $5 \mathrm{~s}$ as shown in the T-s diagram Figure 1 (b) the work output is defined by Eq. (11).

$$
w_{t}=\left(h_{4}-h_{5 s}\right) \eta_{t}
$$

The turbine has single inlet and outlet and assuming adiabatic process and applying Eq. (1) under these conditions, the turbine exergy destruction is given by Eq. (12).

$$
I_{t}=\left(h_{4}-h_{5}\right)-T_{o}\left(s_{4}-s_{5}\right)-w_{t}
$$

The cycle thermal efficiency is defined by Eq. (13)

$$
\eta_{\text {th }}=\frac{\text { net powerout }}{\text { Input }}=\frac{w_{t}-w_{p}}{q_{p}}
$$

The exergetic efficiency of the cycle is given defined by Eq. (14)

$$
\eta_{\text {ex }}=\frac{\text { Net exergy output }}{\text { Exergy input }}=\frac{w_{t}-w_{p}}{\psi_{p h}}
$$

Utilization ratio is the ratio of the available energy to the total supplied energy and defined by Eq. (14). 


$$
\begin{aligned}
& \phi=\frac{\text { primary heat input }- \text { total exergyloss }}{\text { primary heat input }} \\
& =\frac{q_{p h}-I_{\text {total }}}{q_{p h}}
\end{aligned}
$$

\section{Solution methodology}

Once the models that represent each component process are developed, they are interlinked with simulation model. Furthermore, to analyze both the first and second law performance of each component and the whole cycle, thermodynamic properties at the inlet and outlet of each component at the known state are required. To achieve this a subroutine is developed on EES environment. Hence, thermodynamic properties can be collected from EES known the condition of a state point.

\section{Results and discussion}

In order to parametrically investigate carbon dioxide Rankine (Transcritical) cycle performance, availability ratio, and component irreversibilities are simulated with the following assumptions and input conditions. The compressor efficiency, turbine efficiency and effectiveness of the regenerator are assumed to be $0.9,0.9$ and 0.95 , respectively. The pump inlet pressure is assumed to be $6.2 \mathrm{MPa}$.

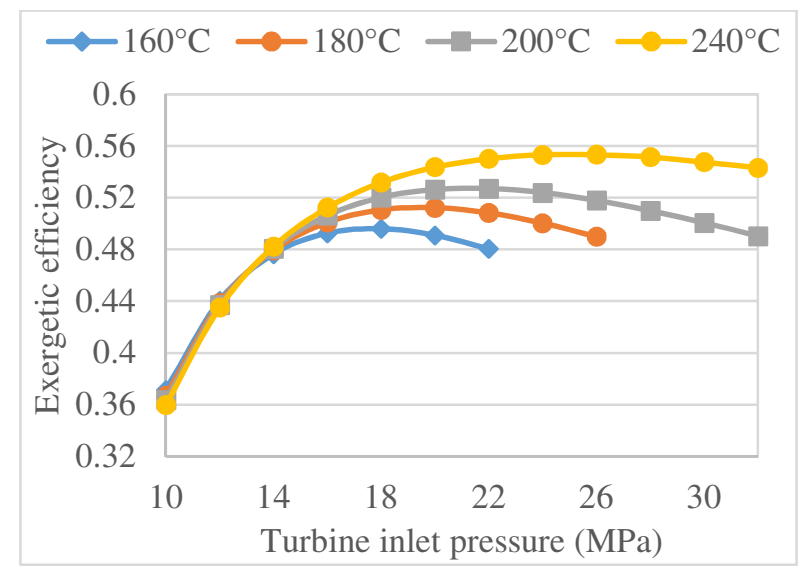

Figure. 2. Variation of thermal efficiency with respect to turbine inlet temperature.

Figure 2 indicates the variation of the thermal efficiency of the cycle with respect to turbine inlet pressure for different turbine inlet temperatures. As can be seen, for a given turbine inlet temperature its efficiency increases as the turbine inlet pressure increases, reaches maximum and gently reduces. Furthermore, at a given turbine inlet pressure, the higher the turbine inlet temperature, the higher is the thermal efficiency. At a given turbine inlet temperature the cycle is simulated until the regenerator contribute heat addition to the compressed carbon dioxide, beyond the last point pressure the regenerator has a reverse effect because temperature of the $\mathrm{CO}_{2}$ leaving the turbine becomes lower than the compressed $\mathrm{CO}_{2}$ temperature. 


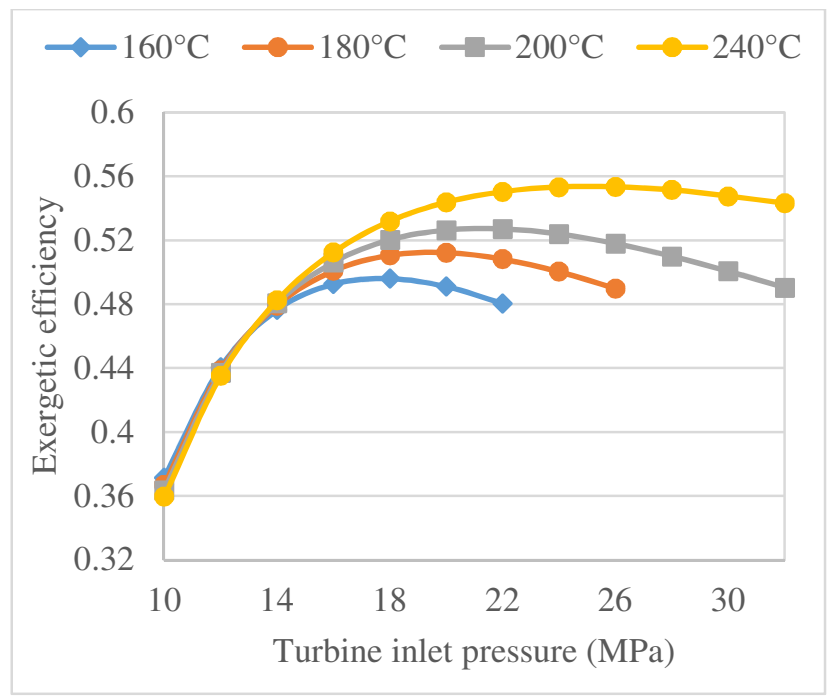

Figure. 3. Variation of exergetic efficiency with respect to turbine inlet temperature.

Figure 3 shows the exergetic efficiency variation of the cycle with respect to the turbine inlet pressure for different turbine inlet temperatures. Unlike the thermal efficiency, it increases rapidly, reaches maximum and then decreases with turbine inlet pressure. Turbine inlet temperature does not have effect on the exergetic efficiency until the pressure reaches $14 \mathrm{MPa}$, after that the higher the inlet temperature, the higher is the exergetic efficiency. The exergetic efficiency is higher than the corresponding thermal efficiency. This is because the denominator used in thermal efficiency is heat whereas in the exergetic efficiency the equivalent exergy was used which is smaller than the heat.

The cycle irreversibility is analyzed parametrically at $10 \mathrm{MPa}$ turbine inlet pressure as shown in Figure 4 (a).

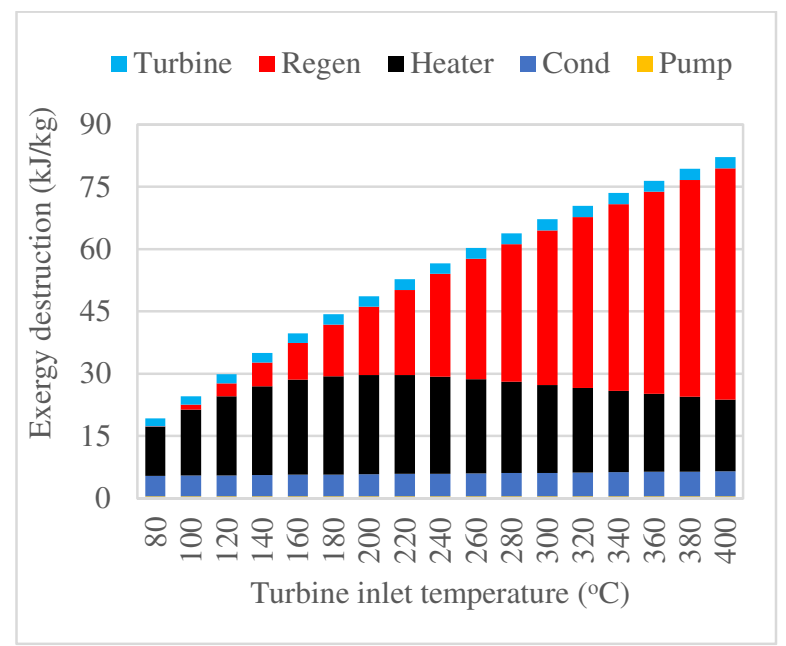

(a) 


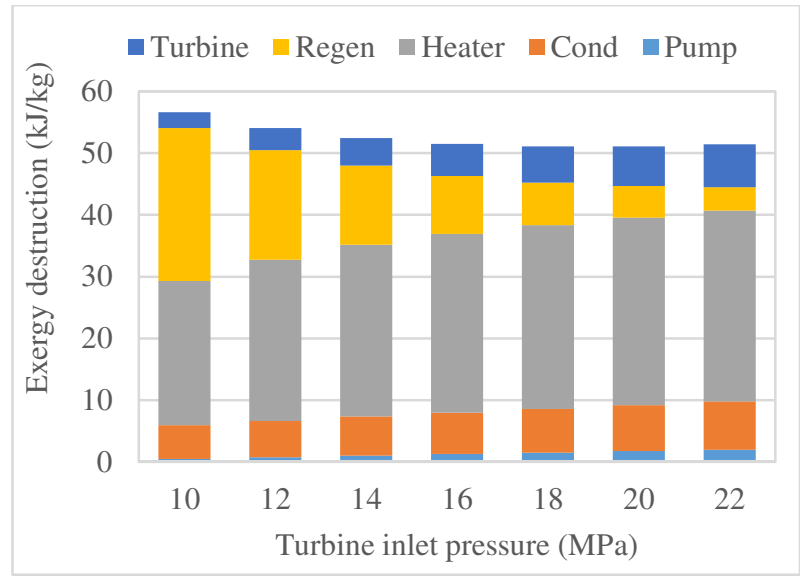

(b)

Figure. 4. Components and cycle exergy destructions, (a) Effect of turbine inlet temperature at 10 MPa turbine inlet pressure, (b) Effect of turbine inlet pressure at $240^{\circ} \mathrm{C}$ turbine inlet temperature.

Overall, the total irreversibility increases as the turbine inlet temperature increases. This is because higher temperature is always associated with irreversibility during heat transfer. The exergy destruction in the regenerator increases as the turbine inlet temperature increases because the temperature gradient between the turbine exit and the compressed gas increases. The percentage of exergy destructions at $240^{\circ} \mathrm{C}$ turbine inlet temperature are $0.94,4.53,9.55$, 41.23 , and 43.74 by the pump, turbine, condenser, heater and regenerator, respectively. The highest destruction happened in the regenerator and the smallest in the pump. In order to reduce the exergy destruction, a better heat exchanger design should be used in the regenerator. Figure 4 (b) shows the effect of turbine inlet pressure on irreversibilities at $240^{\circ} \mathrm{C}$. Furthermore, the total exergy destruction is gently declining as the turbine inlet pressure increases at these given conditions.

Figure 5 describes the effect of turbine inlet temperature on the thermal efficiency and utilization ratio. As can be seen, the thermal efficiency increases whereas the utilization ratio decreases with turbine inlet temperature. This is because the thermal efficiency does not consider the irreversibility. As mentioned in Figure 4 (a) the total irreversibility is increasing as the turbine inlet temperature increases, as a result the utilization ratio decreases. The intersection of the two curves is an optimal working condition of the cycle. Therefore, at 10 MPa turbine inlet pressure $240^{\circ} \mathrm{C}$ is the optimal operating conditions.

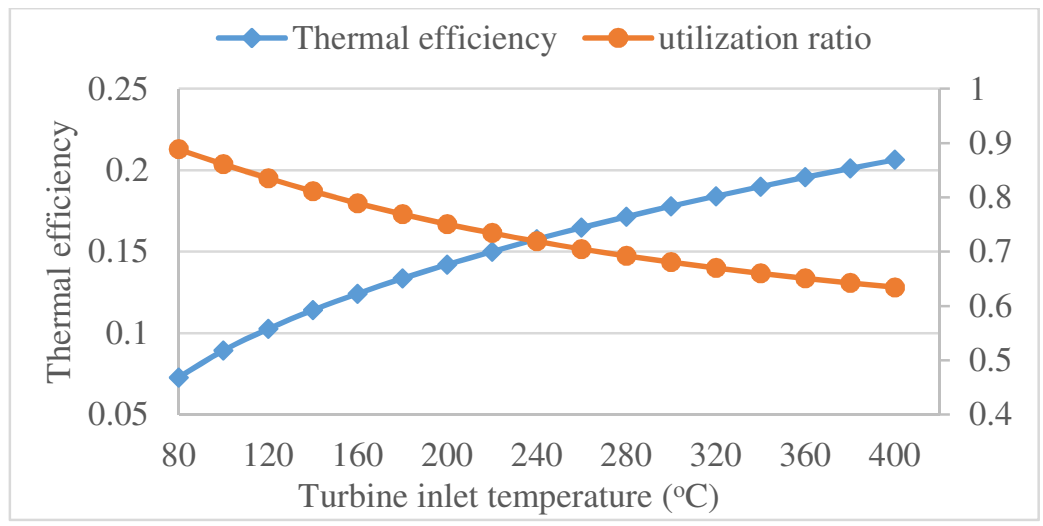

Figure. 5. Effect of turbine inlet temperature on thermal efficiency and the utilization ratio at $10 \mathrm{MPa}$ turbine inlet pressure. 


\section{Conclusions}

A TCRC has been modeled for performance analysis purpose. The component models are interlinked by simulation model which is written on EES professional software environment. EES is also used to evaluate the working fluid properties at the given conditions. In the analysis the following figure of merits: cycle thermal efficiency, exergetic efficiency, utilization ratio and the exergy destruction of the components are considered. For simulation purpose compressor efficiency, turbine efficiency and effectiveness of the regenerator are assumed to be 0.9, 0.9 and 0.95 , respectively. The pump inlet pressure is assumed to be 6.2 $\mathrm{MPa}$. It is found that at $10 \mathrm{MPa}$ turbine inlet pressure $240^{\circ} \mathrm{C}$ is the optimal turbine inlet temperature operating condition. For a given pressure the total exergy destruction increases as the turbine inlet temperature increases. The percentage of exergy destructions at $240^{\circ} \mathrm{C}$ turbine inlet temperature are $0.94,4.53,9.55,41.23$, and 43.74 by the pump, turbine, condenser, heater and regenerator, respectively. Hence, the regenerator and heater are the components that have the highest exergy loss. They are the potential components for further improvement.

Financial support for this research was provided by Ministry of Higher Education, FRGS grant number 0153AB-I70. The authors would like to thank Universiti Teknologi PETRONAS for providing supports to conduct the project.

\section{References}

1. Y.M. Kim, C.G. Kim, and D. Favrat, Energy, 43, p. $402-415$ (2012)

2. Y. Chen, P. Lundqvist, P. Platell, Appl. Therm. Eng., 25, p. 2041-2053 (2005)

3. Emmanuel Cayer, Nicolas Galanis, Martin Desilets, Hakim Nesreddine, and Philippe Roy, Appl. Energ., 86, p. 1055-1063 (2009)

4. Y. Baik, M. Kim, K. C. Chang, and S. J. Kim, Appl. Energ., 88, p. $892-898$ (2011)

5. T.C. Hung, T.Y. Shai, S.K. Wang, Energy, 22(7), p. 661-667 (1997)

6. Y. Chen, P. Lundqvist, A. Johansson, P. Platell, Appl. Therm. Eng., 26, p. 2142-2147 (2006)

7. H. Chen, DY. Goswami, EK. Stefanakos, Renew. Sust. Energ. Rev., 14, 3059-3067 (2010)

8. Y. Chen, Novel cycles using carbon dioxide as working fluid. Licentiate thesis. (Stockholm, Sweden: School of Industrial Engineering and Management; 2006)

9. J.P. Roy, M.K. Mishra, Ashok Misra, Energy, 35, p. $5049-5062$ (2010)

10. J. Wang, Z. Sun, Y. Dai, and S. Ma, Appl. Energ., 87, p. 1317-1324 (2010)

11. T. Ho, Samuel S. Mao, R. Greif, Energy, 42, 213-223 (2012)

12. Young-Min Kim, Dong-Gil Shin, Sun-Youp Lee, and Daniel Favrat, Energy, 49, 484$501(2013)$ 